\title{
La perspectiva ecológica y el discurso teórico de la educación
}

\author{
JOAQUÍN GARCÍA CARRASCO \\ Universidad de Salamanca
}

\begin{abstract}
SUMMARY.-The concept of the environment has been paid special attention by the field of ecology and its study has been approached using analytical and explanatory criteria, while at the same time maintaining a protectionist attitude that is also in favour of a sustainable development. In this study the environment is taken as a perspective from which to study the Total Agent of educational processes. Using this approach, reasons were found for reconstructing the function of space in educational strategies, the role of the «outside» in institutional processes and the function of the complementary in curricular plans and designs. Intervention with respect to the enviroment, to situations, is constituted as a mechanism for promoting educational effects in subjects and a new field of responsabilities to be responded to culturally.
\end{abstract}

\section{DIMENSIONES O ESTRATOS EN EL FENÓMENO EDUCACIONAL}

Si sintetizamos grandes dimensiones o perspectivas en los procesos educacionales, habremos de reconocer -tanto por observación a primera vista, como por tradición científica, como por documentación bibliográfica- que en lo que denominamos educación quedan comprometidos (i) estados y procesos mentales (tanto puramente cognitivos, como afectivos, como perceptivo-motóricos), los cuales se pretenden favorecer y optimizar $^{1}$ (sacarles partido); (ii) estados y procesos de recepción y manipulación de material simbólico valorados personal y socialmente ${ }^{2}$, respecto a los cuales se interviene, en par-

1. Valga como mero ejemplo y alusión Fodor (1986), La modularidad de la mente. Un ensayo sobre psicología de las facultades (Ed. Morata, Madrid).

2. A partir del material simbólico disponible y dispuesto por un sujeto se elabora y forma la orientación de su criteriología de selección para, de entre los elementos del medio, adherirse o emplear aquellos que se transformen en objetos de estima y se configuran las correspondencias con los valores de distinción que posee su comunidad: de un lado se forma en general el gusto por determinadas cosas y se consigue con su efecto la distinción. Según las normas que se apliquen en cada caso (éticas, estéticas, de veracidad...) a cada proceso de estimación - de cosas, conocimientos, o secuencias de acción socialse va configurando el sistema general de comportamientos del individuo y del grupo que merezcan/des- 
te, mediante la planificación de secuencias curriculares o el planteamiento de políticas culturales que inspiren y dirijan procesos más difusos de dinamización cultural ${ }^{3}$; (iii) acciones y procesos de interacción y participación social los cuales se estimulan e inducen creando situaciones, componiendo escenarios e institucionalizando las condiciones que permitan el ejercicio de las competencias y roles de los individuos dentro del sistema social $^{4}$; (v) por más que en todos los casos implícitamente aludimos a iniciativa, como que andamos queriendo e intentando que ocurran las cosas que aludimos, en los procesos formativos de la persona tienen lugar amplios márgenes de influencia social inconsciente, tanto para quien la recibe y elabora como para quien o quienes la originan y producen; hasta se da el caso de que la influencia procede de las circunstancias que rodean a los individuos, el conglomerado de espacios, acontecimientos, acciones y comunicaciones del espacio vital de los sujetos o al que accede mediante los medios de comunicación social.

\section{EDUCACIÓN Y SU ENTORNO}

Todos estos procesos tienen lugar en un espacio y tienen como marco de referencia el tiempo. El espacio y el tiempo son los dos factores que componen y señalan los márgenes plausibles histórica y contextualmente de las utopías educacionales. Si bien los procesos psicológicos son atendidos en las teorías educacionales y en las propuestas de intervención pedagógica, como también son atendidos los procesos de transferencia de los sistemas simbólicos y el progreso de la socialización, el espacio y el contexto histórico no han sido suficientemente tenidos en cuenta ${ }^{5}$. El primero porque en la cultura occidental el espacio generalmente se considera mero escenario y el único y verdadero objeto de dominio para el hombre ( espacio coloquialmente es el hueco en el que ocurren las cosas y no el ecosistema $)^{6}$. No aparece en las teorías de la educación el espacio, el medio, el entorno, el ambiente (no hacemos la enumeración para marcar las diferencias entre los términos, sino para sugerir el verdadero y completo referente) en el puesto de privilegio que merece. Aunque se reconoce que el proyecto educativo se dificulta seriamente cuando tiene que ir contra el ambiente, sin embargo, fieles a la concepción ancestral del espacio, el prototipo de la intervención pedagógica es la denominada ac-

merezcan la atribución de bieneducado o maleducado. Sirva como ejemplo de estas consideraciones el magnífico estudio de sociología cultural y de la educación de Bourdieu, Pierre (1988), La distinción. Criterio y bases sociales del gusto (Ed. Taurus, Madrid).

3. Un problema didáctico interesante es el que plantea la obra siguiente: Zarate, G. (1986), Comment enseigner une culture étrangère (Hachette, París).

4. A este respecto afirma con agudeza Peter J. Wilson: «Una vez que surge la especie Homo sapiens la evolución humana se vuelve un relato del desarrollo de la 'cultura': un inventario de productos hecho posible por la energía cerebral y la aptitud del cuerpo para convertir el pensamiento en acción». Cfr. Wilson P. J. (1984), El hombre como promesa. Las condiciones de la evolución humana (Ed. F.C.E., México), p. 27.

5. Martín Sosa y otros (1989), Educación ambiental. Sujeto, entorno, sistema (Ed. Amarú, Salamanca). En especial se alude aquí al cap. 4 «Educación y ambiente. El espacio educativo» (J. G. Carrasco) y «Sujeto, identidad y medio ambiente» (J. M. Marinas).

6. Claval, P. (1968), Régions nations grands espaces (Ed. LITEC, Paris). 
ción educativa y no el proceso de creación de circunstancias o el de transformación de situaciones ${ }^{7}$.

En nuestros días, el espacio cada vez ocupa un lugar más destacado en las reflexiones; se puede indicar un trabajo de A. Pérez Gómez como el indicador de expansión de esta perspectiva entre nosotros: se dio en llamar el paradigma ecológico ${ }^{8}$. Hoy en día en pedagogía junto a la educación ambiental también está cobrando importancia la educación intercultural. Por ejemplo, europeismo o conciencia europea en el análisis de los procesos educativos indica, antes de nada, que la educación y los educadores reinterpretan la función del espacio, europeizarse es cambiar-ampliar el espacio cultural de referencia, tanto en cuanto ámbito del que recoger los materiales con los que se elabora currículo, como espacio de locomoción humana en el que los individuos encuentran los materiales con los que fabrican su propia identidad.

Pero también dijimos que los factores epocales o históricos aún no habían tenido el lugar que merecen en el discurso pedagógico. Con ello queremos indicar que aunque se han producido análisis muy agudos y esmerados de las circunstancias que rodearon a los procesos educacionales y a los sistemas pedagógicos en cada tiempo, no se conocen también los procesos que la época -la de la sociedad en su evolución y la de la edad en la maduración del sujeto- producen en la formación de la persona. No encuentro con asiduidad referido el tiempo como agente de maduración o agente de inestabilidad-reequilibramiento de la persona.

\section{EL OBJETO PREVALENTE DE LOS DISCURSOS EDUCATIVOS}

A lo anteriormente expuesto se añade que la unidad paradigmática habitual de análisis educativo es el individuo $(\mathrm{N}=1)$ hasta el punto de que en muchas definiciones la educación se reduce a su personal e intransitivo proceso de maduración; pero entorno para un sujeto no es solamente la dimensión física, ni medio ecológico o perspectiva ecológica significa con exclusividad el entorno físico -natural o construído-, sino que nuestro medio activo influyente es el que componen los demás en nuestro mundo; la importancia de los grupos de referencia, del medio humano, reemplaza el lugar que tiene en la jerarquía de principios de actividad la cadena trófica para el resto de los seres vivos.

La interacción y la transacción $(\mathrm{N}=2)$, aunque se reconoce, -por ser más abstractaes menos sistemáticamente estudiada como sujeto de educación y no es fácil encontrar una justificación teórica sólida que justifique el enunciado, p.e. «sistema de relación maestro-discípulo, o de educador-educando». Porque hablar de sistema es aludir a una unidad; lo inhabitual es el estudio de la unidad, el análisis de la relación educativa en cuanto tal, la perspectiva transaccional de la educación. Se ha escrito y se escribe mucho sobre relaciones educacionales, pero muchas veces la preocupación se centra en lo que tiene que hacer, o en el modo de comportarse uno con otro de los polos. La relación mis-

7. Freire, P. (1990), La naturaleza política de la educación. Cultura, poder y liberación. (Ed. Paidos MEC, Madrid).

8. Pérez Gómez (1982), Investigación en el aula y paradigma ecológico, Ponencia en el I Congreso Internacional de Didáctica, Murcia. 
ma se escapa, por lo cual no se advirtieron problemas y consecuencias no previstas: el estrés de los profesores, los factores de riesgo de la profesión pedagógica...

Pero, lo que aún es más infrecuente, salvo en los discursos sociológicos, es que la unidad de análisis de los procesos educacionales sea la comunidad $(\mathrm{N}=\mathrm{n}+2)$; lo fue para algunos autores de la época de la Ilustración para los que tenía sentido hablar de la «educación de los pueblos»; esta es la razón de que en los tratados de Pedagogía no se encuentre sistematizado el campo de las políticas culturales. Nos referimos a la comunidad como objeto para la iniciativa y la intervención pedagógica. Por haber quedado fuera es por lo que la animación cultural queda en los intereses académicos y en la actividad profesional como una cuestión marginal y voluntarista.

Esta situación explica la sorna con que un compañero, que observó en mis manos el libro de Pierre Gerbet ${ }^{9}$, me dijo: ¿Te dedicas, ahora, a la construcción de Europa?. Los cambios que están teniendo lugar en Europa, las consecuencias que se derivan para las políticas culturales y para los planes curriculares, son el dato alarmante que necesitan las teorías educacionales para definitivamente incorporar el espacio como elemento de definición $-\mathrm{y}$ no como mera preocupación ecológica $-{ }^{10}$ y para definitivamente aceptar que el marco de referencia siempre ha de ser el tiempo. El capítulo primero de la obra de Dilthey Fundamentos de un sistema de pedagogía ${ }^{11}$ lleva por título: «La inconsistencia de los sistemas predominantes de pedagogía que buscan principios de validez general para la educación de todos los pueblos y de todas las épocas».

\section{IMPLICACIONES DE LA PERSPECTIVA ECOLÓGICA}

La antropología habitual, la más reconocible y entendida como antropología, contiene elementos que funcionan como muros de separación y fosas insalvables -saltos dialécticos para algunos- los cuales casi ni tienen necesidad de declararse explícitamente o afirmarse, se encuentran anidados, casi diría agusanando, el lenguaje coloquial y la semántica habitual de las palabras:

\section{a) El dualismo materia-espíritu}

Evidentemente la materia sería la masa de la que se encuentran fabricadas todos los componentes del mundo, y el espíritu lo otro de lo que se encuentra fabricada la parte más prístina y propia del ser humano. Sin negar los motivos de esta demarcación, las perspectiva ecológica ha de encontrar algún resquicio, algún ángulo de visión por el que y desde el que se pueda aplicar con sentido el nosotros implicando la totalidad de los elementos con los que nos encontramos relacionados; eso es lo mismo que emplear términos que enuncien el vínculo, la relación y la dependencia. Como consecuencia modi-

9. Gerbet, Pierre (1983), La Construction de l'Europe (I. National, Paris).

10. En este punto la pedagogía española es deudora por interés que ha introducido por estos temas al Prof. Toni Colom Cañellas. Cfr. Sureda, Jaume-Colom, Antoni (1989), Pedagogía ambiental (Ed. CEAC, Barcelona).

11. Dilthey, Wilhelm (1965 v.o. 1874), Fundamentos de un sistema de pedagogía (Ed. Losada, Buenos Aires). 
ficaremos la percepción racional del mundo y en vez de identificar la naturaleza con lo simple (lo burdo, lo primitivo, elemental, la materia prima, el recurso...), dado que somos tan naturaleza como lo que más, la imagen natural se tornará el modelo de la complejidad, de la simetría, del orden, de lo evolucionado, de la terminación primorosa. El mundo que no se admira no induce en quien puede proponer y plantear normas el criterio activo de la conservación, del desarrollo sostenido...; más bien la dualidad engendró el comportamiento salvaje con el mundo que debe ser la sorpresa y el desconcierto de cuantos seres tengan la capacidad de observar y sufrir el comportamiento humano. Toda la materia a la que hemos podido cognitivamente acceder es materia organizada; todo comportamiento de ser vivo que hemos podido estudiar es comportamiento complejo; toda la estructura que sorporta el comportamiento dirigido por la inteligencia del hombre y el resto de su comportamiento está integrada por materia organizada. El vínculo, la pertenencia al conjunto es la definitiva perspectiva desde la que soportan un sistema simbólico ecológico que incluya al hombre y un sistema ético en el que el criterio de valor de la norma incluya el reequilibramiento del ecosistema, ya que desde la destrucción del medio como en el caso del resto de los seres vivos también toma origen la muerte del hombre, la muerte inducida no la natural y evolutiva

\section{b) La dualidad cuerpo-mente(alma).}

La verdad en antropología y el sentido y valor de las acciones más típicamente humanas, más etológicamente específicas, contiene habitualmente la necesidad o el presupuesto de una dualidad ontológica. Olvidamos que es elemental principio de epistemología que el elemento abstracto se infiere del concreto y del observable a primera vista (prima facies) o interponiendo mediadores sensoriales de los que tenemos constancia racional de garantía interpretativa. El espíritu es el elemento abstracto de la realidad que indagamos y su mediador son las acciones. El acceso al espíritu de forma ordinaria y corriente lo pretendemos a través o por la mediación de los comportamientos humanos más propios y exclusivos, la tonalidad espiritual a la que se accede -muy occidental, por cierto- es el del espíritu-otra-cosa, es el del espíritu-otro-mundo, con este espíritu llegamos a la separación...

Nos falta un tanto indagar el espíritu a través de la actividad del hombre natural, del hombre en el mundo; tal mediación llevará a percibir un espíritu integrado y que se integra y que necesita para su espiritualidad, para el acceso a la espiritualidad la progresión en la naturalidad muy oriental, por cierto. Este es un ecumenismo y una interculturalidad a la que nos resistimos. Pero, tengo pocas dudas acerca de que cualquiera que tenga mal comportamiento con el entorno (el que componen todos los seres) es que está pensando mal o equivocadamente sobre lo que menosprecia de palabra o menosprecia de hecho al destruirlo. Cuando Sócrates identificaba el mal con la ignorancia, aludía al proceso cognitivo en el que toma origen y condición la acción no-ética.

No queremos afirmar con lo dicho anteriormente que la manera de cambiar los comportamientos sea indefectiblemente la de cambiar los conocimientos, tesis hegeliana; ciertamente la acción y el pensamiento se modifican mediante la creación de contextos en los que la acción a la que el contexto propende y refuerza es la acción que prescribe la norma. Pero, aquí y ahora, los comportamientos agresivos e irreflexivos sobre el me- 
dio, sobre todo medio - parece como si el instinto humano se dirigiera hacia la desvinculación y el menosprecio del contexto- animan su propensión destructiva y la refuerzan como consecuencia del sistema simbólico en el que la identidad personal es la otredad ontológica radical, la otra parte del dúo.

\section{c) La dualidad racionalidad-de-la ciencia de-la-naturaleza-racionalidad-ciencia-de-la- conciencia}

La racionalidad de la ciencia que estudia los denominados fenómenos naturales se tranquiliza cuando accede a constructos interpretativos de gran simplicidad y de textura proposicional muy cerrada y estricta. Esta epistemologia contiene coloquialmente la aspiración a la generalidad, al lenguaje universal... Las humanidades, las cosas humanas, la ciencia del hombre (la de su exclusiva propiedad objetiva y subjetiva) son en cambio el ámbito de la ciencia de la diferencia y de lo insólito. En la pelotera se dan dos banderías que se mandan andanadas respectivamente; los pelotazos más repetidos son: «eso no es ciencia» (por las humanidades); «eso es inservible» (por los cientificos naturales). Casi ninguno sobrepasa su trinchera -como es propio de toda guerra- para situarse en ese terreno común (volvemos al ecosistema, espacio común, no sólo por coincidir en él todos, sino porque todo lo que se encuentra en él está vital naturalmente interrelacionado) en el que el científico descansa del estudio de la causalidad lineal, los choques elásticos, y las reacciones reversibles para atender a las preguntas acerca del valor y la ética; y en el que el filólogo... el «hombre de letras» apura su reflexión con los datos de la ciencia y no con meras narrativas coherentes sobre macanas.

\section{EL EMPUJÓN DE LA ANTROPOLOGÍA}

Un camino a medias de corrección de perspectiva es el que han recorrido muchos antropólogos. Se encontraron una tradición en la que se compartimentaban en moradas diferentes las cosas materiales, los seres vivos, y el hombre. Rompieron un tabique y redujeron los ámbitos a dos habitaciones: Pleroma (lo no viviente) y creaturas (todos los seres vivos) (en Andalucia, las criaturas-criaturitas son únicamente las personas humanas, máxime si está necesitada). A partir de ahí se esmeraron en atender y estudiar la pauta que conecta ${ }^{12}$ a todas las creaturas. De ahí surge la psicofisiología, la etología... El peligro que acecha lo constituyen los denominados cierres categoriales, los mecanismos cognitivos mediante los cuales la definición-delimitación de un conjunto de fenómenos en una categoría se lleva a cabo por reducción fenoménica del conjunto al nivel más bajo de la expresión de tales fenómenos. Tales reducciones también se practican por arriba y suelen llevar a la negación de la propiedad. Es la manía de decir que los animales no son inteligentes, que los animales no sienten, que el hombre domina sobre el entorno, que el comportamiento animal es reactivo... etc. Elementos para el descubrimiento de la pauta que conecta son las homologías orgánicas (semejanza de formas entre organismos), homologías comportamentales (semejanza de patrones de comportamiento entre etogramas de organismos diferentes).

12. Bateson, Gregory (1990 v.o. 1979), Espíritu y naturaleza (ed. Amorrortu, Buenos Aires). 
Debe existir un ámbito de actividad racional en el que el problema que se plantea se formule, cuando se ha derrumbado el otro tabique y entonces se investiga la pauta que conecta al hombre con todo; pero no para describir lo que del hombre es un puro fenómeno físico y qué del organismo es una estructura atómica, sino para plantear la unidad existencial que más nos interesa: el ser-con-lo-demás-en-el-mundo.

\section{LAS IMÁGENES MENTALES}

Junto a las anteriores dualidades se producen opciones intelectuales, por la dificultad que entraña tratar de abarcar con conceptos la totalidad del espectro. En el lenguaje coloquial y en muchos discursos, por historia de las palabras y huellas de discursos anteriores y hasta como medida prudente por por parte de los autores en vistas a prevenir «descarríos intelectuales», se opta por uno de los extremos de las polaridades anteriores. Tales opciones se contienen en las imágenes mentales del discurso, en las analogías y metáforas preferenciales.

Cuando hablamos de perspectiva ecológica no podemos olvidar que se trata de eso y, por lo mismo, no es suficiente con introducir un nuevo capítulo en nuestras preocupaciones o escribir un nuevo libro. Cuando el tema estudiado es tan envolvente, como el ambiente, nos obliga a cambiar de sistema de pensamiento. Voy a tratar de insinuarlo y con ello justificar el conjunto de reflexiones que siguen .

Aunque pueda parecer sorprendente, la percepción sensorial, el lenguaje coloquial como cristalización de categorías conceptuales y las imágenes mentales con las que nos comunicamos acerca de la educación -lo que comunicamos acerca de la educación-, no tiene nada que ver con lo que denominamos perspectiva ecológica.

Nuestra percepción sensorial, tal y como se anida en las palabras ha entendido los fenómenos educacionales fundamentalmente como procesos de influencias que tenían como soporte la comunicación: verbal por las enseñanzas (instrucciones, consejos, órdenes...) y no verbal por los ejemplos/modelos, exhibición de sistemas de comportamientos. De tal suerte que si excluyéramos de los elementos que componen la visión habitual de los fenómenos educativos el elemento magistral/educador, físicamente contenido en personas, vaciaríamos el discurso y nos quedaríamos sin realidad a primera vista. En esta primera visión el ambiente es mero escenario.

La estructura habitual del acto educativo, estructura que mis alumnos nunca han tenido la necesidad de estudiar en las clases de Pedagogía, la aportaban de casa ya muy elaborada, se compone de agente, sujetos, acciones y procesos, y enseñanzas. Aun con esos componentes la complejidad de los discursos ya llegó a ser grande.

En este modo de ver las cosas se originan dos consecuencias importantes para el objeto de nuestras reflexiones aquí: la primera que, desde tal fragmentación del contexto, no se puede ver lo que realmente es el ambiente, nuestro entorno, ni el papel que juega; la segunda, que si se alude en algún momento a educación ambiental, lo directamente aludido es profesores, alumnos, enseñanzas en torno al tema del medio ambiente. Algo parecido a lo de la educación sexual, moral, social o religiosa. La primera intención es la de cambiar los contenidos de los libros de texto, para enseñarle a la gente que el medio que menospreciamos y dilapidamos es nuestro medio de vida; nos preocupamos por las doctrinas ecologistas y por meter en doctrina a nuestros alumnos. En tal caso estamos 
solamente dentro del modelo habitual de ver las cosas de la educación, de la misma manera como se veía en tiempos de Berceo, cuando educar a alguien se decía hacerle discípulo, disciplinarlo, meterle en doctrina.

Esto es muy importante, porque parece mentira que una cultura tan sofisticada como la propia del área geográfica europea haya sido tan insensible con el entorno físico, en cuanto a la interpretación de su valor formativo -no meramente estético-; incluso fue más sensible para la modificación que para la destrucción. Hacer un canal de riego, un río artificial, planteaba dudas filosóficas; talar un bosque para ver mejor la ciudad sitiada era perfectamente razonable. $Y$ es que la cultura grecolatina consiguió interesarse ideológicamente por el futuro del hombre, pero no por el futuro de la Tierra, ni del paisaje. El verdadero antes y el verdadero después era teológico. Entre ambas fronteras únicamente merecía ser salvado el hombre, ni siquiera Roma.

Así las cosas a lo más que podemos aspirar es a la educación ambiental (educación acerca del medio), nunca a una Pedagogía Ambiental (educación tomando como instrumento de la acción el medio más que la palabra, la palabra sería el acompañamiento o la música de fondo), como acaban de titular un libro mis buenos y perspicaces amigos $\mathrm{T}$. Colom Cañellas y J. Sureda ${ }^{13}$. Ellos mismos nos recuerdan, yo también lo he gritado, que no pueden hacernos errar la tradición americana y francesa; la primera, entiende la teoría y la acción educativa, todo lo más como práxis reflexiva, ni académica ni científica; la ciencia de ésto es Psicología Educativa o de la Educación, Filosofía de..., Sociología de...; la segunda mucho más expedita de lengua, Francia ha sido un buen criadero de grandes decidores, zanjó con lo de Ciencias de la Educación. La educación no les aparece un objeto de conocimiento científico como otros, sino «situación (problemática) que se debe solucionar desde otras perspectivas científicas», comentan los dos autores citados. Convengo con ellos en que educación ambiental, para mucha gente, es la estrategia didáctica, el diseño formativo con que resolver el problema gordo que tenemos de la mala educación generalizada en el trato con el medio físico, natural o construido. $\mathrm{Ni}$ que decir tiene que Pedagogía Ambiental es un término impropio que no me he encontrado, por el momento, en ningún libro sobre estas cosas, más que en los que empiezan a escribir pedagogos. ¡Cuándo llegará la hora en que escribir defendiendo la razón de la Pedagogía y de la Pedagogía Ambiental, sea una pérdida de tiempo! Evidentemente, no porque la Pedagogía pase al estado anterior al que tenia antes de su propio big-bang en el siglo XIX, sino por algo, tan lejos aún, como el momento histórico para el conocimiento pedagógico en el que todo aquél que se tire en plancha a estudiar procesos educativos, con cualquier metodología, se sienta ufano de decir y tratarse como pedagogo, en vez de separarse gremialmente del objeto que está estudiando, por considerar mejor catalogación la de Sociólogo, Historiador, Psicólogo... Ahora ya hay quien se bautiza como Técnico del Curriculum, o Didacta, o.... Encima de la mesa tengo dos Actas de Congreso, la una de Sociología y Medio Ambiente y la otra de Psicología y Medio Ambiente; ni un solo trabajo sobre educación ambiental; varios si, sobre cómo se modifican las conductas con determinados cambios ambientales. El que hiciera aportaciones p.e. a recursos y estrategias de modificaciones o construcciones de espacios físicos para generar motivos en el aula..., estaba haciendo Pedagogía, si no quiere ser llamado Pedagogo, es un problema personal y no un problema de la Pedagogía. ¡Cuántos bioquímicos son por titulación académica médicos, biólogos, químicos o farmacéuticos!.

13. Sureda, J., Colom, A. T. (1989), Pedagogía Ambiental (CEAC, Barcelona). 
Yo creo que esta cuestión aparentemente tan sólo gremial está en el origen de no poder construir buenos planes de estudio para la formación de profesores. La solución puede venir por una conducta de dinosaurio que consiste en comerse toda la pradera; ya tenemos Psicología Escolar, Psicología de la Educación, Psicología Ambiental..., tendremos Psicología del Curriculum...

Mucho antes de que se hicieran Congresos sobre Psicología Ambiental, se habían construido sistemáticamente ambientes pedagógicos como instrumento para la consecución con/sin éxito de metas formativas. Cito, por un poner y amontonadas, unas pocas: Las escuelas al aire libre del Padre Manjón, Las Ciudades educativas, las Escuelas Freinet con sus talleres, sus imprentas... etc., las escuelas granja de Milani, las Colonias Gorki... Por cierto, un tratado de Pedagogía Ambiental tendría que completarse con una relectura de los clásicos y una reobservación de los diseños pedagógicos institucionales. Los científicos que no tienen, por oficio, la acción educativa en su punto de mira permanentemente llegan a ella para alejarse.

\section{COMPLEJIDAD DEL ESPACIO DE ACCIÓN EDUCATIVA}

Pensando según el modelo lógico elemental de una interacción entre sistemas, actuar es complicarse la vida, educar es complicarnos en la vida de los demás. En otros términos actuar es definir un entorno en que quedan coimplicados (complicados) varios sistemas dinámicos. La definición de cada aspecto ya no se puede llevar a cabo sin contar con el resto que define el entorno. No se puede definir el ratón sin los componentes del medio que le sirven de alimento, sin la tierra que le sirve de guarida, sin los detritus que le sirven de camada, sin los congéneres que selecciona para su reproducción, sin el ave de presa que lo devora. Como tampoco podemos definir la acción educativa que se origina en el profesor sin tener en cuenta al alumno, sin la cultura que define los patrones de la acción favorable, sin los instrumentos que amplifican y median en la acción, sin el entorno social.

Analicemos el modelo desde el aspecto por el que representa un sistema de acción altamente complejo.

Si alguna palabra está en la boca de los profesores y de los educadores en general esa es la de complejidad. Cuando acudes a cuanto sabes o has experimentado y sugieres alternativas y salidas a las situaciones que plantea la enseñanza o la educación de los hijos, la respuesta constante es: «no es tan sencillo». Es un dilema lo que se nos plantea. $\mathrm{Si}$ se proponen soluciones, aparece el rechazo; si no proponemos soluciones, aparece el rechazo también porque se supone que debe haber quien las conozca. Todo parece apuntar, en ocasiones, hacia la tranquilidad que produce la sensación de impotencia. Sentirse impotente y generalizar la impotencia tiene los mismos efectos que las curas de reposo.

La complejidad del fenómeno educativo es frecuente que los profesores la definan como «son muchas las cosas que intervienen en este asunto», con lo que dan a entender que para cada variable considerada la ecuación que la represente tendría infinidad de huecos o incógnitas. Ante tal complejidad cabe la actitud de quien abandona su iniciativa a la corriente dominante de opinión o a las justificaciones personales que, al tiempo que bajo el ropaje discursivo encarnan meras acomodaciones del estado de cosas personal (lo que cada uno lleva dentro) que lo enrasan con las circunstancias construyendo 
para ello «racionalizaciones»; en esos casos, la teoría de la educación que cada uno carga es la racionalización del propio comportamiento y se queda en la gloria. Lo que las reformas educativas, por el contrario promueven, es el fomento de la actitud científica, la cual aquí no significa inicialmente otra cosa que indagar en las situaciones y no rendirse, para que la relación pedagógica no termine siendo, en algunos casos, un diálogo de disminuidos psíquicos: un educador que se cree escultor (delirio) y fija el modelo para tallarlo -si no se deja- incluso a golpes, por el bien de la estatua; y un educando que armado de energía vital y del medio de vida que le proporcionan cree que la vida puede ser mera espontaneidad y juego de deseos (delirio). Muchas veces observo situaciones en las que el sistema de relación pedagógica aparece con «la realidad perdida». La actitud racional se rige por tres principios y los tres tienen que ver con el mundo y con la realidad, con la «ambientación».

(a) Entre los principios que manejan los científicos el primero y principal es tan directo y sencillo como una pedrada. Se trata de la hipótesis realista: el mundo es objetivo, las cosas ocurren, podemos observar sin por ello alterar el mundo; las propiedades de la percepción contienen particularidades de la cosa en sí, por más que de la condición estimular potencial del universo nuestros órganos sensoriales no reciban más que paquetes con sentido. El método científico es un procedimiento para alertarnos de que a partir de lo percibido prima facies podemos llegar más lejos corroborando lo que suponemos. No nos puede caber la menor duda: se dan sucesos en el hombre que merecen la categorización de educación y aunque intentamos meter nuestra iniciativa en el asunto, comprobamos que son muchos más los acontecimientos educacionales, conformadores de personalidad, que tienen lugar sin contar con ella ni con la de nadie.

(b) El segundo principio es el que denominamos hipótesis parcialmente determinista. Los acontecimientos del mundo no son independientes entre sí; en este principio se asientan las leyes y el conjunto de sucesos virtuales que las mismas prohiben. La gente no desarrolla su configuración comportamental, ni la aplica de una manera $u$ otra, por mera energía endógena. La estructura de las consistencias y de las contingencias del comportamiento dependen de la historia anterior y de la información actual que llega al individuo desde el medio. Pero siempre encontramos un margen del funcionamiento del mundo y del comportamiento de los hombres que parece errático y a la buena de Dios. No por falta de instrumentos o fórmulas que representen el mecanismo, sino porque también se da un margen de indeterminación y aleatoriedad cuyos límites hace más oscuros la creatividad humana.

(c) El tercer principio lo denominaríamos hipótesis histórica: Los enunciados que representen cosas del mundo (objetos, relaciones o acontecimientos), si son ciertos, nunca deben ser contradichos, por más que indaguemos el caso en contra. Y, cuando nos llevamos la sorpresa de la contradicción por los hechos, hemos de cambiar los enunciados. El comportamiento in-esperado -fuera de la regla, inarmónico- lleva frecuentemente al desconcierto y hasta a la desesperación (no olvidemos que, cuando se puede, muchos profesores todavía expulsan de clase a los indóciles, los quitan de enmedio). La actitud científica nos obliga a los pedagogos a considerar la situación-problema más que como una contrariedad como un caso en contrario: invita a indagar; si nos lleva a la irritación, a claudicar, a salir por los cerros de Ubeda, en el fondo demostramos que no sabemos a qué atenernos. La mejor manera de que el acontecimiento nos envuelva en su bruma es 
implicarnos personalmente en la situación; en la educación -aunque trabajemos con niños encantadores y tiernos- es imprescindible la distancia que objetiva las situaciones. El «contra» despertará curiosidad e investigación en la práctica, en lugar de levantar dolores de cabeza. Ello supone que, como cualquier otro especialista, la situación es observada desde el equipamiento pedagógico de que se disponga. Si no se tiene, se tiene poco o de poca calidad, cada uno mirará a su aire con el riesgo frecuente de que se vayan las cosas de las manos.

Con estos tres principios nos ponemos en marcha para conocer lo que de la realidad se nos oculta o por demasiado grande, o por demasiado pequeño o por demasiado complejo.

\section{LAS IMÁGENES MENTALES DE LA INTENCIONALIDAD}

Las imágenes mentales explican en parte nuestro pensamiento; es la imagen mental la que busca la metáfora en vistas a la concreción lingüística del pensamiento. En la educación, cuando proponemos una finalidad, da la impresión que hemos puesto un punto en algún sitio y pretendemos caminar hacia él. Lo que realmente observamos, cuando escamoteamos el señuelo del lenguaje, es que el hombre se acerca hacia sus metas del mismo modo que se expande el agua en el suelo horizontal: en todas direcciones, o en una más que en otras, dejando el perfil de una curva cerrada sin centro observable. Mejor sería si la imagen la construyéramos en tres dimensiones, o en espacios multidimensionales. Al mismo tiempo que nos acercamos al fin llegamos y alcanzamos muchos otros lugares.

Volvemos a encontrarnos de nuevo con una precisión sobre la complejidad; el fenómeno educativo obedece en amplia medida a dos regularidades características de los ecosistemas en la naturaleza: en amplios aspectos del mismo el comportamiento aparece errático; así como apreciar puntos críticos donde pequeños errores aparentes producen grandes efectos, o pequeñas iniciativas desproporcionados beneficios. La perspectiva ecológica nos enseña que, en verdad, lo que cada cual pone en su nicho funcional dentro del ecosistema global, o la medida en la que afecta al sistema comportamental de un sujeto, por lo general son minucias. En pedagogía esto es claro: uno enseña matemáticas un curso, otro ejercicios corporales, .... El sistema global de influencias es el que realmente explica la trayectoria. La teoría de la educación es frecuentemente hiperbólica.

A veces hemos reaccionado ante la alusión de que la pedagogía es un arte, porque tal vez entendemos el arte como despropósito, como la pura expresión sin proyecto. Pero son los mismos procesos psíquicos, las mismas estructuras mentales las que producen la ecuación, componen una sonata, redactan un poema o dirigen el trazo de una pintura. Las cuestiones decisivas, la experiencia nos enseña, que siempre son pormenores.

Los enunciados que condensan objetivos o propósitos instruccionales o educativos, al mantenerse año tras año, dan la impresión de que nos encontramos ante hechos reproducibles. Al disponer de las cifras de éxitos y fracasos y obtener porcentajes, interpretamos estos hechos como fenómenos estadísticos regidos por la probabilidad (la de la ruleta, la del juego). Aquí no estamos ante cuestiones de azar, sino ante una reproducibilidad de éxito en el aprendizaje que no se da por sí misma, sino que hemos de realizar esfuerzos técnicos para conseguirla. 


\section{9. ¿DÓNDE SE EDUCA LA GENTE?}

En el lenguaje coloquial, tan acuciante como la pregunta acerca de ¿qué es la educación? -que no se lo pregunta nadie-, es la de que ¿cómo conseguir educar? y ¿Dónde lo mando para que se eduque?. Cuando el desastre adviene suelen con dolor lamentarse diciendo: «anduvo por malos sitios».

Descubrir los espacios de máxima incidencia en el comportamiento de la gente es encontrar claves de educación. Traeremos a colación algunas reflexiones históricas.

\section{AÑORANZA DE LA VIDA EN EL CAMPO}

Tal vez como recuerdo de la vida en la pradera y de la simplicidad de la vida humana en la horda primitiva, en la que la lucha por la sobrevivencia se establece entre el propio cuerpo y los recursos naturales -es decir, en guerra limpia y noble-, ha sido constante la añoranza de la vida en el campo, entrar en contacto con la naturaleza. Ese es el contenido, provocador de sentimiento para los espectadores, que trasmite Aristófanes en Los acarnienses y en La paz.

«Miro a lo lejos, hacia mis campos, enamorado de la paz, me horroriza la ciudad y añoro mi pueblo, que todavía no me ha dicho nunca: compra...» (Los acarnienses, vv. 32-36).

«...ardo en deseos de volver a los campos y remover la tierra con mi almocafre... ¡Recordad hombres la antigua vida...!» ( $L a ~ P a z$, vv. 569-579).

Una iniciativa de la perspectiva ecológica es la de evitar en la medida de lo posible que las fotos y los párrafos reemplacen la información que se adquiere a partir de la información directa. La mediación de la escritura ilustrada hace perder significatividad cultural y dificulta muchas veces el aprendizaje significativo, porque se olvida que el alumno llega a tal objetivo de aprendizaje sin imágenes mentales en las que soportar su actividad cognitiva.

\section{DENTRO Y FUERA COMO NORMA}

Dentro y fuera de los espacios formativos de referencia ha sido siempre un criterio y norma de educación. El prototipo de esta perspectiva ha sido la importancia concedida a lo largo de la historia al papel formativo del viaje, ver mundo, entrar y salir.

Según estima Plutarco, el medio familiar es más blando y laxo con los niños, en cuanto al rigor con el que que hay que acomodar el comportamiento a los requerimientos de una cultura como la espartana. Las calidades comportamentales que requiere la fuerte competitividad, requieren la creación de espacios formativos extrafamiliares, «evitando la laxitud de una educación hogareña y demasiado blanda...». Los muchachos espartanos sólo permanecían con sus familias hasta los siete años. Junto a la contracción de los sentimientos, a la dureza de los ejercicios físicos... se les enseñaba a no temer en la oscuridad, ni tampoco en la soledad. El contraste más fuerte con el medio familiar lo proponía uno de los ritos y aprendizajes propios de la entrada en la vida adulta se encon- 
traba la práctica de la criptia. El joven debía vivir solo en el campo, como un licantropo, oculto, practicando la caza nocturna y debiendo capturar esclavos y matar al menos uno.

El mecanismo básico de formación de las culturas tradicionales es la vida cotidiana, en la cual quedan reflejadas todas las actividades propias del modo de vida de un pueblo y su sistema simbólico. La aparición de instituciones específicas para la educación será una consecuencia de la complejidad de la estructura social. Las normas pedagógicas primitivas dictan comportamientos para la vida del niño en la ciudad, y la circulación del mismo en ella. No se preocupan por los contenidos. La teoría de la educación contemporánea corre el riesgo de centrarse en la educación formal, la de los sistemas e instituciones de enseñanza -esta es la que tiene más teoría-, cuando ha sido la última en llegar y cuando la otra no ha perdido ni un ápice de su influencia. No olvidemos que a esa otra más cotidiana y penetrante se denomina, se supone que sin mala intención, informal. La perspectiva ecológica obliga a resituar la teoría de la educación de manera que ocupe en la representación conceptual de la teoría el lugar y papel que cumple en la vida real, para no crear ilusiones en los profesionales de la educación.

El primer espacio pedagógico institucionalizado fue la casa de aquella persona que asume la función de educar: tal es el caso del citarista, del gramático, incluso del profesor de gimnasia infantil. El joven y el adulto practicaban los ejercicios físicos en la palestra.

Desde muy antiguo se responde socialmente al hecho de que en cada generación hay que reimplantar los patrones culturales de comportamiento. Tal función se da simultáneamente con la de convivir y cumplir otras misiones sociales perentorias; de ahí que rápidamente aparezca la suplencia en las funciones educativas. Entre los comisionados de la educación el más temprano es la nodriza. Para todos los que conocen este servicio saben que no es meramente de nutrición. Y así lo proclama la nodriza de Orestes en Las Coéforas de Esquilo. Y de las manos de la nodriza, cuando era posible, el niño griego pasaba a las manos del pedagogo. En muchos libros de Pedagogía aparece como el esclavo que acompañaba al niño a la palestra. Es ganas de no querer entender lo que ocurria entonces. «Este era un esclavo destinado a su persona, que tenía la misión de acompañarle a todas partes y de enseñarle buena educación ('la cortesía pueril y honrada'), recurriendo, si era necesario a castigos corporales, con fustas sobre todo. El pedagogo le acompañaba por la mañana a casa del maestro y le llevaba la cartera.... ${ }^{14}$. Le esperaba al salir o le acompañaba en clase y así podría repetirle luego las lecciones. Esta figura social cumple perfectamente la funciones de tutela y cuidado, y vigilancia activa del comportamiento. Pretender inferir o justificar la misión del pedagogo actual a partir de este rol primitivo es una tontería. El rol social del profesional de la educación no es el producto evolutivo de aquellos esclavos, sino la consecuencia de la evolución del Sistema Social en su conjunto, los otros como muchos son todos precursores.

En el espacio en el que cumple la función el maestro la silla en la que se sienta difiere de todas las de los demás de la sala, niños o pedagogos.

La educación se reduce a cuestiones de conducta en el espacio y en el tiempo, de cuanto se hace en cada espacio y en cada momento; y en cuanto a calidad, se miraba la excelencia con la que se podrían practicar las acciones en las que más se fijaba el colec-

14. Flacelière, R. (1989 v.o. 1957), La vida cotidiana en Grecia en el siglo de Pericles (Ed. TH, Madrid) p. 122. 
tivo. No se planteaba sistemáticamente la cuestión del diseño de contenidos, ni de la técnica más eficaz para conseguirlos. El aprendizaje de la lectura y la escritura era largo y penoso. Lo que está claro es que en cada espacio de educación lo que todos los actores pretendían no tenía nada que ver con el instrumentalismo de una enseñanza para el día de mañana, sino más bien con la enseñanza de lecciones vitales. Homero aparece como maestro de vida. El maestro de música enseña a tocar la cítara o el oboe, y con ello practicaban el canto, y con el canto melodiosamente repetían las letras de los poetas tradicionales en la que se contenía en verso el alma del pueblo griego.

Las personas y las instituciones sociales actuaban cada uno acorde a su papel social y mediante procedimientos incrustados en los patrones de conducta colectivos, unos por otros aprendían. Ninguno se hizo cuestión de que enseñarle a otro la excelencia ciudadana pudiese convertirse en tarea y función, en profesión para la que debía cualquiera ser formado. Esto ocurre con el sofista y no para enseñar a los niños sino a los adultos. Con ellos se instituye el espacio social del conocimiento, el espacio para las personas que quieren dedicar su tiempo a saber. Esta institución fue ideada por los pitag6ricos. El primer carácter que adquiere es el de cofradía religiosa, bajo la advocación de dioses o Musas.

En el caso de los sofistas esta práctica del conocer no tiene lugar propio, allí donde esté el maestro. En rigor, sus enseñanzas finalmente se orientaban a preparar a los individuos para el dominio de la situación, esta es la excelencia que mejor reconoce el pueblo, es la del gobernante, la del hombre de posición, la del orador influyente, la del demagogo. Los sofistas consideraban que tal calidad podía ser aprendida y fomentada. Hoy, diríamos que se trataba de una educación para el éxito social. Sócrates les criticaba que pretendieran saber de todo, que supusieran que la virtud -la virtud moral- puede ser directamente enseñada y que cobraran por su actividad docente. Colocado tan alto en Sócrates el ideal del conocimiento, la Universidad que funde Platón, no es un lugar para la enseñanza y el aprendizaje, sino un lugar religioso.

En el fondo, esto ocurre porque culturalmente aún no se ha resuelto, todavía andamos en ello, como unir el conocimiento y la vida cotidiana. El saber sacaba del mundo y elevaba al hombre, el saber para vivir no tenía academia. Es aquí donde empieza eso de crear espacios para el conocimiento. Hoy por urgencia histórica andamos buscando conocimientos para el espacio, para defender el espacio aunque estemos nosotros con nuestras ideas y proyectos; en lugar de crear espacios de conocimiento, intentar conocer lo que está pasando aquí.

La mayor interdependencia entre hombre y medio la mantenían culturalmente los hombres que practicaban trabajos manuales, especialmente el agricultor. En Grecia este trabajo era despreciado. La realidad de las instituciones educativas en la actualidad, en muchos aspectos de la relación entre el individuo y su entorno, siguen siendo herederas de estos hábitos sociales y de estas ideologías.

\section{EL ESPACIO INSTITUCIONAL}

Se generalizaron las escuelas de primeras letras y, a partir de los doce años, las escuelas de gramática. Tanto en Grecia como en Roma la escuela no es un espacio propiamente formativo de ciudadanos o preparador profesional, se trata de un espacio para el adorno cultural, la excelencia, o el embellecimiento cultural, para la práctica de las be- 
llas artes; digamos que estamos en una especie de perfumería de la cultura. Lo propio de la escuela romana es la retórica. Con la diferencia de que en Grecia la escuela es una continuidad de la práctica de estética social y la romana es un producto de importación completamente al margen. En Grecia la palestra puede ser lugar adecuado para la enseñanza de las letras, porque era el cuerpo la clave de la estética social en concordia con los ideales populares del noble guerrero. En Roma, en cambio, es la cultura de la palabra, la oratoria. En ambos casos, la intervención y el ejercicio de la función pública no se entiende como actividad profesional especializada, sino cometido de un hombre digno, una persona privada ideal ${ }^{15}$.

Quien no accede a tales cargos públicos es un hombre sin importancia. La importancia se obtiene con el papel y el sitio en la escena pública. Esta actitud no se ha perdido, entre nosotros también se valora la importancia en función de indicios como lugar que se ocupa en asambleas, frecuencia y lugar de aparición en los medios de comunicación social, lugar de la vivienda en el plano de la ciudad: por el lugar y posición en el espacio humano. La búsqueda de importancia en la ciudad es una carrera que no termina mientras se tengan posibilidades, de ahí deriva la actividad de mecenazgo, la oferta de diversión al pueblo, la construcción de teatros y circos ...por parte del cargo público; es la búsqueda del favor de la multitud, el término que la designa (ambitus) está claramente conectada con la idea de espacio, conseguir posición.

El prototipo de una persona privada lo define así Peter Brown y otros: «individuo libre y nacido libre, opulento y cuyos bienes de fortuna no son recientes, hombre de negocios bien educado e incluso cultivado, desocupado, pero que disfruta de una dignidad política ${ }^{16}$.

Frente al padre de familias se encuentra la indefinición del espacio vital del esclavo. Sus relaciones carecen de importancia social, su vida privada es un espectáculo que se contempla con desdén; del mismo modo que su nombre pertenece a una categoría onomástica particular (como los nombres de perro); la psicología del amo no es como la del esclavo: su alma carece de autonomía Tal actitud es la de la acomodación mental a un espacio vital concreto, mediante ella se produce el menor sufrimiento y se protege la estructura de la personalidad. Mientras los ciudadanos podían considerar ideales de cultura, el esclavo siempre consideró como ideal la consecución de la libertad, ese era el eje de su comprensión del mundo. La Teoría de la Educación desde el concepto no toma en consideración estas variantes; la reconstrucción social de la educación debe tener en cuenta estas variantes que se producen desde la función-posición de los individuos y grupos, dado que una de las consecuencias de la mejora de equipamiento es la de «mejorar la situación», lo que no puede conseguirse casi nunca si la intervención es meramente sobre los sujetos y no sobre las situaciones. La perspectiva ecológica obliga a considerar las situaciones como objetos de intervención pedagógica, el fenómeno educacional no es exclusivamente sistema de acontecimientos personales, también -quizás sobre todo- sistema de acontecimientos sociales. Ya hemos aludido que en el pensamiento pedagógico corriente no hay sitio, no encuentra su sitio, en el cuerpo del discurso y no en co-

15. En la actualidad puede considerarse como obra capital sobre la educación grecolatina la de llsetraut Hadot (1984), Arts libéraux et Philosophie dans la pensée antique (Etudes Augustiniennes, Paris).

16. Brown, P., Patlagean, E. y otros (1987), Historia de la vida privada. t. I Del imperio romano al año 1000 (Taurus, Madrid), p. 163. 
rolarios lejanos, la animación cultural de entornos, donde la intervención más que concretarse en intervenciones de actores se concreta en la introducción de «vertidos»: creación de instituciones, acomodación de espacios...

\section{LUGAR DEL OCIO Y EL LUGAR DEL TRABAJO}

En la antigüedad, la diferencia entre el pueblo y la ciudad estribaba en que en ésta vive la clase noble que posee vida privada u ociosidad. La actividad del noble se cubre con todo menos con el trabajo asalariado. De ahí que el que tiene vida privada (nobleza) es el genuino candidato para la gestión de la cosa pública. La tienda, el taller, el campo de labranza... es el lugar para los hombres moralmente inferiores; el pleno ideal de humanidad se encuentra al margen del trabajo manual y de la actividad comercial. De ahí que riqueza es posibilidad de virtud. La riqueza raíz es la de la posesión de tierra, de bienes inmuebles, no es la que se obtiene ni siquiera de la actividad comercial.

Estas valoraciones empleaban los argumentos más extravagantes. La calificación no se adjudica en función de la especificidad de la tarea, sino de la apreciación colectiva de la tarea desde el exterior. El noble lo será, aunque se meta en negocios; el zapatero es zapatero. En ambos casos se trata de una óptica pública y no de la naturaleza de las cosas. En el fondo no se menosprecia el trabajo, sino que se menosprecia socialmente a quienes tienen la necesidad de trabajar para sobrevivir.

Además del espacio para el trabajo existe el espacio para el ocio, en él tienen lugar los placeres y los motivos para la admiración: los espectáculos en el circo o en el teatro, la grandiosidad de los edificios públicos y la configuración misma de la ciudad. La gente se admiraba con los prodigios de la tecnología que introducía maravillas en el espacio construido: las carreteras, los túneles, los canales, los puentes, el sifón que salva un valle en el acueducto, el cuadrante solar... La mirada perdida del visitante de la ciudad patrimonio nacional o de la humanidad, con la mirada perdida y la cámara de fotos: sin este modo de recorrer el espacio no se poseería la noble condición, para muchos envidiable, de ser turista.

Del mismo modo que la mente más cultivada dicta la norma del pensamiento y la interpretación del mundo, el espacio considerado como de más calidad (el espacio urbano) dicta la norma del comportamiento: la urbanidad. Las reglas de comportamiento entre el gobernante y los gobernados tenían más importancia, para el juicio de éste, que la misma decisión política o comercial que promovía.

\section{URBANIDAD EN LA PERCEPCIÓN DEL ESPACIO HABITABLE}

Al decir urbanidad nos referimos al estilo propio de los notables que, salvo personalidades muy cultivadas e ideológicamente muy sofisticadas, eran la admiración y la aspiración de cualquiera. El grupo dominante en el Imperio Romano era la nobleza urbana. La fundamentación de su nobleza estaba en el patrimonio y el elemento más radical del mismo estaba en la tierra. El campo era la fuente originaria de su dinero, pero no el lugar de su trabajo. El campo se convertía en espacio de vida tan solo en meses de verano. La naturaleza sólo era lugar de placer y amenidad/divertimento. El valor se podía exhi- 
bir en prolongadas sesiones de cacería. De ahí que la naturaleza más apreciada era la domesticada en la ciudad en forma de parques y jardines. La ciudad no es ni apreciada ni percibida por el notable desde el hacinamiento y hediondez del extrarradio romano o la ciudad baja de Atenas, ni el prototipo del ciudadano era el liberto sin destino o el menestral que sobrevivía con dificultad; la ciudad por excelencia era la que se disfruta en los baños públicos o se admira en la fachada de los edificios oficiales. El si mismo del ideal romano sólo se encuentra en la ciudad. La ceremonia de identidad ciudadana más propia es el banquete, es un acto social más que alimentario. Del banquete, el período más noble es el final en el que se bebe y se conversa; hasta llegó a crear un género literario.

Todavía entre nosotros guarda la comida su condición de ceremonia social y hasta se ha preservado la última parte, con más bebida que comida, como momento para las explosiones expresivas, la conversación deleitosa o el cierre de los negocios.

La parte convivencial del pueblo llano, con menos fastuosidad y refinamiento tenía lugar en sitios como las tabernas y las cofradías (collegia). El origen de estos últimos fue la asociación de gentes de la misma orientación profesional y de todas las categorías sociales. Estaba formada sólo por hombres y la organización semicopiaba a la de la ciudad; resumiendo tenían carácter devoto, social y festivo, repitiendo el banquete como acto central. Desde la perspectiva de hoy diríamos que se trataba de una fastuosidad y ritualización de la sociabilidad colectiva. Tiene la ventaja de aumentar la ocupación de la mente por la fiesta: el antes se magnifica con la espera y la preparación, el durante con la dilatación del acontecimiento (las comidas más largas son las de las solemnidades colectivamente celebradas...) y el posterior con el recuerdo y el comentario. Ello explica el lugar que ocupa en la antropología y filosofía humana del momento la fiesta; y en la imaginería, el dios Baco. En él se representaba la idealización del placer y de la fiesta colectiva.

El otro espacio de la comodidad ciudadana eran los baños. Eran construcciones públicas en las que alcanzaba al plebeyo la oportunidad de calidad de vida propia del noble. Cumplía funciones similares a las de las playas en los veraneos actuales.

Además de los baños, otro espacio de nivelación social, por ser público y colectivo, eran los anfiteatros. Las funciones sociales y colectivas son análogas a las que cumplen en la actualidad los estadios y los cosos. La función política y social asignada a los espectáculos nunca es públicamente minimizada. Ningún otro recinto ha significado tanto, ni jugado un papel social tan relevante en la historia de occidente, salvo las catedrales. La misma posibilidad de existencia de tales recintos exige una configuración determinada en la estructura sociolaboral, en la que únicamente fue posible.

Todos estos comentarios que anteceden insinúan que una educación ambiental no es meramente la que tiene por objetivo la reconciliación del hombre con la planta y con el animal, sino la de la reconciliación del hombre con su espacio vital. Pero también advierten que las imágenes que nos hacemos del espacio y que arrastran nuestros conceptos, mero escenario, no hace justicia con su importancia antropológica ni con el papel fundamental que ha jugado y que juega en la dinámica de la persona. Debemos darnos cuenta que nos hemos educado en una tradición histórica con esos patrones interpretativos y que hemos de estar muy alerta para que no se escapen todos los indicios que deben ser atendidos desde una perspectiva nueva para un occidental. Cuando nos situamos en un nuevo punto de vista lo primero que hemos de conseguir es aprender a ver, ejercitar la visión. 


\section{REORIENTACIÓN DE LA PERSPECTIVA}

Para la interpretación correcta y la valoración de la importancia que corresponde a los procesos educacionales característicos de la «influencia del entorno» se han de tomar en consideración varios hechos:

a) La intervención educativa es necesaria en el ser humano, lo que se manifiesta porque «el abandono integral» durante largo tiempo -si mantiene posible la sobrevivencialo dejaría antropológicamente irreconocible. Es el caso de los denominados niños lobo, o niños abandonados a su suerte en edades muy tiernas. Pero nótese que aquí el abandono es abandono a su suerte sin la transacción cotidiana con los demás: carencia de entorno humano.

Pero, incluso, mantenida la inserción en el espacio convivencial, las «carencias básicas» en el sistema de relación con los adultos origina perjuicios frecuentemente irreversibles. Decimos ésto para tener en cuenta que los procesos de transacción educacional que son necesarios e imprescindibles son los que tienen lugar dentro de la dinámica ordinaria del sistema convivencial. De hecho la escuela dentro de la evolución humana es un hecho relativamente reciente en parámetros temporales, los Sistemas Educativos en toda regla no aparecen en Europa antes del siglo XVIII. Luego lo primario para el desarrollo humano ha sido la relación formativa extraescolar. La escolar es la evolución, desarrollo, complejización de la primera. Aún hoy se dan culturas denominadas fósiles en las que no aparece ningún rol que pueda asimilarse al nuestro de profesor, ni ninguna institución que mereciera la denominación de escuela; sin embargo poseen sistemas de transmisión cultural, procesos de información sobre tradiciones, habilidades técnicas... etc.

b) El espacio social original de la relación pedagógica ha sido el espacio familiar (trama de parentesco), el espacio de intervención entre iguales (trama sociotélica), y el espacio de cooperación social orientado a la supervivencia del grupo (trama orgánica social). Esto vale para los adultos y para los niños. Entre estos últimos el espacio original fue un espacio físico señalizado y construido para la sobrevivencia del grupo de referencia. Existía una señalización clara de un espacio «para el domicilio» y un espacio «para el libre movimiento protegido». Las ventajas evolutivas que representaron estos modos de vida para la configuración del sistema de comportamientos individual, ni son suplantadas por la Institución Escolar, ni pueden ser totalmente asumidas por ella, ni han sido eximidos de las mismas los padres, los iguales, los interlocutores, dentro de nuestras sociedades complejas. Esas comunidades que se describen en las utopías sociales en las que los niños se educan fuera de los grupos de referencia originales, no pasan de ser experimentos mentales. Por el momento el abandono, el hospitalismo y otros fenómenos análogos que el individuo vive e interioriza como apartamiento y abandono... originan síndromes comportamentales disfuncionales. El espacio primordial para la maduración personal y formativa del hombre sigue siendo, por el momento, el espacio familiar y el espacio social del grupo de referencia. La Escuela es un espacio formativo complementario de alto poder, sobre todo en la dirección del equipamiento cognitivo y ocupacional, y también en lo social; la escuela respecto a esas funciones no es como un teléfono supletorio; en términos de sistemas de acción, no son sistemas equivalentes. La actividad extraescolar humana es actividad antropológicamente primaria. 
El progreso en la solidaridad orgánica, o de dependencia de roles, es correlativo con el aumento de la complejidad del sistema social. La configuración institucional de los proyectos sobrevivenciales colectivos y los propósitos de calidad vital, llevan en épocas recientes a la configuración de roles educacionales específicos. Los ejes básicos y más antiguos de estructuración de la influencia colectiva han sido:

\section{IMITACIÓN O MODELADO}

- Aprendizaje dentro de contexto, o aprendizaje a través del ejercicio y ensayo de la propia secuencia de acción que se quiere aprender, pero en la que la realimentación del proceso se lleva a cabo mirando como hacen los adultos cuando están haciendo lo mismo que yo.

- Aprendizaje fuera de contexto, o aprendizaje donde las secuencias de acciones del que aprende tienen lugar fuera de espacio y de tiempo de la acción real que desea aprenderse. En general podríamos decir que el aprendizaje tiene lugar a través de la simulación. La ventaja del procedimiento es obvia, al menos en sistemas de acción de alto riesgo; en la cultura del noble guerrero queda clara la utilidad del procedimiento dado que se encuentra en juego la vida. El Sistema de Enseñanza es la gran simulación del Sistema Social

- Autoformación mediante el juego serio, y la combinatoria de patrones junto a la intersección de artefactos-herramientas. Es el sistema que constantemente emplea el niño pequeño utilizando objetos inicialmente fuera de toda norma, y mediante el cual ensaya, combina y recombina patrones de comportamiento, resuelve problemas; en los patrones de actividad psicomotórica va insertando objetos y herramientas, con lo que se ensaya todo un proceso de formación cultural autoinstructivo creativo.

A pesar de cuanto venimos diciendo el discurso pedagógico es fundamentalmente intraescolar, porque predomina la advertencia de la ventaja social de estar escolarizado, frente a la importancia antropológica primaria -para la maduración, el desarrollo y el equilibrio- de las transacciones sociales extrainstitucionales. Desde un punto de vista antropológico la actividad extraescolar no se cuestiona, en tanto que la actividad escolar es una elaboración y reestructuración de objetivos primarios que tenía aquella, y no al revés.

b) La introducción de mediadores de la comunicación social, con la aparición de efectos de marginación cuando falta su dominio, aumenta la complejidad de las competencias: Algunos de estos mediadores que amplían los procesos y mecanismos de formación son:

(i) La lectoescritura que en determinadas condiciones representa una extraordinaria ventaja para la transferencia y fijación de información, y para la fijación de estructuras del sistema social... Pero al tiempo que representa una ventaja, cuando ya se encuentra implantada y generalizada la estructura convivencial que se corresponde con el mediador, surge el problema de la marginación representada por el analfabetismo.

(ii) Mediadores de la acción, representados por todo el sistema de tecnología, herramientas y útiles. 
(iii) Mediadores de la elaboración intelectual, representados por los todos los recursos metodológicos para desarrollar el conocimiento y por todas las elaboraciones mentales (mitos, generalizaciones de la experiencia, reglas técnicas, teorías personales,... y teorías científicas) las cuales actúan como amplificadores de la potencia comprensiva que poseen nuestros sentidos para la comprensión del mundo.

(iv) Mediadores en la percepción de los fenómenos: telescópicos, televisión, para los fenómenos distantes; microscopios de todo tipo o, en general instrumentos para el análisis de los fenómenos de menor tamaño; macroscopios o elaboraciones intelectuales con las que estudiar los fenómenos de mayor tamaño, como las sociedades.

(v) División del rol trabajo y del rol de preparación para el trabajo, situación ésta que llevó a la aparición del rol de profesor. Los expertos secretamente menosprecian la figura de quien inicia en un conocimiento a otro, por el simple hecho de que iniciar requiere menor conocimiento que expandir o hacer progresar el conocimiento, o requiere otro conocimiento y organizado de otra manera que quien lo aplica en concretas secuencias de acción formativas. Por eso Julián de Ribera, arabista español, decía que «quien sabe hace y quien no sabe enseña».

c) En las sociedades complejas el espacio de libre movimiento protegido es regresivo. Entre el espacio colectivo de domicilio y el espacio no ocupado, se sitúa el que antes era protegido y ahora peligroso por la tecnificación de la locomoción (riesgo de accidente), y la desmesura en el espacio ocupado (riesgo de pérdida). En consecuencia:

(i) Se distorsiona el espacio de domicilio por yuxtaposición de la acción doméstica con la lúdica y con la comunicativa social dentro del grupo primario; cuando hay varios niños en una casa y se ponen a jugar, es la locura, en tanto que si juegan en espacios abiertos se dice que no dan guerra. Los niños de nuestras ciudades andan buscando sitio, se han quedado sin él. Por más que hayamos elaborado mucho nuestro comportamiento seguimos siendo organismos con necesidades de territorialidad.

(ii) Degenera el tiempo lúdico y de la combinatoria perceptivo motórica (juegos en los que la motricidad se sumaba a la iniciativa) de los juegos originales, en favor de «juegos quietos» y de la satisfacción de la exigencia lúdica mediante los ejercicios de fantasía: los comics, Tv-vídeo, juegos electrónicos... El niño satisface imaginativamente las exigencias motrices.

(iii) El niño desconoce el uso de la ciudad, debe ser enseñada.

(iv) El niño desconoce el espacio libre extra-domiciliario, debe ser enseñado.

En definitiva, hemos inventado la Escuela -una ventaja indiscutible-pero hemos tergiversado el espacio vital, y ahora tenemos que reconstruirlo: la reconstrucción del espacio vital de los niños, que originalmente le era dado, sin más, ahora tenemos que salvar lo que se pueda mediante iniciativas denominadas de carácter extraescolar.

Realmente son reflexiones teóricas, pero son útiles para poner en su sitio a la Escuela y lo que se denomina el fuera de la escuela: simplemente nuestro entorno. Según Pablo Freire nos educamos unos a otros teniendo como fondo el mundo... 